\title{
El interés de la ortodoxia y la heterodoxia fotográfica en Deseando Amar (In the Mood for Love, Wong Kar-wai, 2000)
}

\section{The relevance of photographic orthodoxy and heterodoxy in In the Mood for Love (Wong Kar-wai,, 2000)}

\author{
Autor: \\ Diego Martín Fernández \\ http://orcid.org/0000-0002-5783-2903
}

Resumen: China esta siendo la protagonista en el año 2020. Pero pocos recuerdan estos días que el 20 de Mayo, Cannes homenajeaba los veinte años del estreno del filme Deseando Amar, con una versión restaurada en $4 \mathrm{~K}$ del negativo original.

Este aniversario es sorpresivamente oportuno, no solo por el país de origen del proyecto, sino también por el sentido en el que la ruptura con las normas clásicas fotográfico-visuales toman forma en el filme, a través de la incomunicación de la sociedad o el olvido, la distancia entre los personajes, los gestos repletos de significados, el encierro, los vacíos o los silencios.

Palabras clave: Fotografía, Cine, Kar-wai, Elipsis, Ruptura.
Abstract: China is at the forefront of 2020. But these days few remember that on 20 May Cannes was to celebrate the twenty years since the premier of the film In the Mood for Love with a restored $4 \mathrm{~K}$ version of the original negative. The anniversary is surprisingly appropriate, not only for the country of origin of the project, but also for the way in which the rupture with classical photographic/visual rules takes shape in the film. This occurs through the lack of communication in the society, the forgetfulness, the distance between characters, the gestures brimming with meaning, the confinement, the empty spaces and the periods of silence.

Keywords: Photography, Film, Wong Karwai, Ellipsis, Rupture. 


\section{Introducción.}

Cannes celebraba este año su 73a edición del prestigioso Festival de Cine y la organización ya ha anunciado su intención de posponerlo hasta finales de Junio o principios de Julio. Momento en el que un reducido grupo de espectadores podrán disfrutar por primera vez de la versión dirigida por Criterion y L'Immagine Ritrovata de la Cineteca de Bolonia, bajo la supervisión de Kar-wai.

China fue el país de origen de este proyecto, gracias a un esquema argumental que giraba en torno a tres historias y un punto neurálgico: Pekín y la Plaza de Tiananmen. Pero la República Popular China no autorizó el rodaje en los exteriores y la idea original debió de ser abandonada. De hecho, gran parte de los decorados se recrearon con total libertad en el hospital militar británico de Kowloon -ya en fase de derribo-.

- El largometraje nos presenta una conflictiva historia en torno a la tradición más respetuosa de la cultura oriental, no solo por la confrontación entre la doble infidelidad o la necesidad, sino por los ambientes que muestran en ella, a pesar de situarse en una ciudad cosmopolita, como es Hong Kong.

- Con un claro estilo manierista (González Requena, 1992:15-22), Wong Kar-wai domina los signos de puntuación foto- cinematográficos para hablarnos de un amor contenido, gracias a un rodaje en el que muchas escenas, las que contienen los elementos más obvios y explícitos, son suprimidas en la fase de montaje.

En el relato reina el uso del fuera del campo, con continuas ausencias de elementos o sugerentes. De ahí que nos invite a apreciar la soledad de los exteriores, en la que los personajes pueden pasear por un callejón o charlar apoyados contra una pared. $Y$ todo lo contrario: la aglomeración de los interiores, sin intimidad y llenos de vecinos tratados como intrusos.

En definitiva, imágenes que realzan el subsuelo de la incomunicación y la soledad de las sociedades modernas.

\section{Objetivos e hipótesis.}

- Defender la actualidad del filme y su trascendencia más allá de lo meramente visual, tanto en cuanto a su alejamiento de las normas del cine clásico, como a la presencia de la elipsis a lo largo de todo el largometraje.

- Analizar cómo el uso de distintos recursos visuales y técnicas fotográficas han servido para adentrarse en las emociones y sentimientos transmitidos a través de la imagen.

Basándonos en estos objetivos, la hipótesis que se plantea es que nos encontramos con un reestreno del largometraje Deseando Amar (2000) totalmente oportuno, no solo por la actualidad de su país originario, sino también porque gracias al dominio de la mecánica fotográfica, al servicio de una historia en la que la elipsis se hace protagonista de la narración, se logró un resultado visual de calidad fotográfica profesional ${ }^{(1)}$.

\section{Metodología.}

Siguiendo una metodología interpretativo-hermenéutica, se procedió a hacer una cuidadosa revisión de la literatura y filmografía disponible, para tratar así de conocer lo que previamente 
escribieron otros autores sobre el tema propuesto, y para poder medirlos empírica y cuantitativamente.

Gracias a ello, se pudo construir una primera hipótesis y, posteriormente, mediante una metodología estructural-cualitativa, realizar un estudio relativamente profundo de los fotogramas más destacados del largometraje, seleccionando un total de 195 imágenes fijas captadas directamente en el mismo, para analizarlas, tanto individualmente, como en la globalidad del filme. De dicha elección basada en que reunieran los distintos elementos a analizar, así como las interpretaciones vinculadas a su función dentro de la narración visual, pudimos comprobar que no se asumían normas estilísticas estables algunas, sino la construcción de unos códigos propios.

\section{Ortodoxia y heterodoxia en relación con el tratamiento fotográfico del filme.}

Para empezar, debemos entender que la ortodoxia es un estado de conformidad con doctrinas, sistemas, prácticas y usos admitidos por la sociedad de forma general. Mientras que la heterodoxia representa el estado de disconformidad ante lo impuesto.

Al caso, sabemos que Wong Kar-wai defiende un cine que no se ajusta a los cánones del modelo de representación hegemónico, desvelando en vez de ocultando. F. J. Gómez Tarín (2013: 15) explica que el MRI - Modelo de Representación Institucional esta basado en la transparencia enunciativa. O lo que es lo mismo, desarrolla relatos como si nadie fuera responsable y eliminando las marcas que desvelen quién es el enunciador.

Académicamente hablando, la ortodoxia fotográfica abarcaría una imagen nítida, enfocada o bien compuesta. En contra, la intervención premeditada del fotógrafo en cualquier instante del proceso fotográfico y la aparición de ruidos tecnológicos, sería un ejemplo claro de la heterodoxia fotográfica o lo que estaría fuera de la norma.

Sin embargo, ambas son normas creadas por distintos momentos históricos y corrientes de pensamiento, como el Realismo -1860-, que fuedecayendo por las consecuencias de la evolución tecnológica del medio fotográfico.

Tan solo hay que mirar hacia la historia de la fotografía para leer que cuando Daguerre o Nadar obtenían un negativo borroso por los largos tiempos de exposición, el resultado era desechado.Pero con los años, Étienne Jules Marey y los hermanos Bragaglia, decidieron usar esos fallos para representar el movimiento con interés científico, hasta que, poco a poco, acabó siendo un recurso más propio de la fotografía, que incluso otros incorporaron al cine o a la pintura. De hecho, Julia Margaret Cameron, que hace de la borrosidad un rasgo estético propio y afrontó cuantiosas críticas por ello, se desvió así de la norma predominante.

Los estereotipos tienen mucho que ver en ello porque reflejan los valores exactos de la cultura reinante. Con esto se separa lo que merece la pena de lo que no merece ser atendido, marcando unas normas de comportamiento que sigue el aficionado en fotografía. Así como el hombre de a pie mira lo que dice el colectivo que mire, lo que está tipificado como interesante y lo que es digno de atención. 
Su actitud podría considerarse ortodoxa, del mismo modo que el profesional que mira lo que dice el mercado que mire. Aunque crea ser un sujeto activo, en realidad es un sujeto pasivo al servicio de un mecanismo preprogramado.

Sin embargo, lo que mira el fotógrafo como autor -y es el caso de Christopher Doyle, el director de fotografía del filme -, se constituye en el acto de la visión. Lo que ve a través de la cámara es distinto a su imagen mental, puesto que no persigue la realidad, sino que se anticipa a la fotografía que aún no existe y que debe realizar:

Tener cierto sentimiento personal hacia el mundo y saber decidir qué camino tomar para expresar o ser más creativo, es algo que nadie puede enseñar ya que depende tan solo del fruto de la madurez personal. (Fontcuberta, 2003: 207)

De hecho, Christopher Doyle y Wong Kar-wai piensan en la película una vez están en pleno rodaje. Por ese motivo trabajan muy bien juntos. Para el director de fotografía, lo visual es fruto de la intuición y la experimentación. Por eso busca el encuadre y a los personajes, dentro de la localización. Además, prefieren el trabajo en grupo para que cada uno pueda aportar su punto de vista.

Como el fotógrafo Humberto Rivas dijo en la entrevista realizada por Manolo Laguillo:

Antes de nada me interesa hacer una fotografía. Luego viene el tema [...]. Pero lo que desencadena todo es tu forma plástica de encarar una determinada cosa. Lo que tú haces como forma, no como técnica -la técnica apoya a la forma-, es lo que da tu manera de ver fotográficamente eso. Dos fotógrafos, frente a una misma escena, la encaran de distinta manera, igual que el mismo individuo encara de distintas maneras todas las cosas. (Laguillo, 1995: 88)

En definitiva, la imagen no convencional es aquella contraria a lo prototípico -infrecuente o extravagante-, en la que se evitan los roles predominantes de la imagen. Es decir, que no responde a las normas que la sociedad ha impuesto o aceptado -lo que ocurre en publicidad, por ejemplo-.

Por eso hay que atender tanto a aquellos autores que siguen un guión, como a los que lo crean conforme la historia va narrándose, como es el caso de Wong Kar-wai. Porque la heterodoxia requiere un aprendizaje por parte del público de nuevas reglas, una recodificación de la interpretación del signo conocido anteriormente como erróneo. Al caso, la obra de Wong Karwai, y en especial Deseando amar (2000), implica activamente al espectador a través de esta mirada que recrea toda una información insinuada. La contención de datos sobre la historia y sus protagonistas, o la escasez de marcos visuales definitorios y contundentes, compromete al espectador: éste debe completar la narración a partir de las pistas que el director despliega ante él con brillantez. El director sugiere, esboza, cuenta desde la desubicación de espacios y la ucronía de tiempos. Mientras el espectador mira, contempla y completa el universo de escenas imprecisas y delicadamente vagas, como si de un "sfumato" se tratara.

\section{Usos compositivos y sus rupturas.}

Una composición es la manera de resolver la imagen y otorgarle estructura y contenido al caos visual ante el que se encuentra, antes de decidir el momento de disparar e imponer su orden. Por eso lla composición puede ayudar a obtener una respuesta emocional del espectador. 
Sin embargo, cualquier fotógrafo experimentado sabe que para entender el comportamiento de la luz, hay que observar a su sombra. Del mismo modo que para lograr representar un objeto de manera abstracta, primero habría que saber hacerlo de modo realista.

De ahí que en este largometraje encontremos distintos tipos de usos compositivos y sus respectivas rupturas:

\subsection{Encuadre.}

Se refiere a la discriminación de una parte de la realidad y su limitación con un marco(2). Ofrece así una porción de lugar que, al igual que un espacio de tiempo, circunscribe el contenido de la imagen y puede simbolizar la totalidad de lo representado a través de indicios mostrados ínfimamente.

No obstante, a través del medio fotográfico es necesario prescindir de ciertos aspectos de la realidad para llegar a su representación fotográfica. Por eso, cualquier delimitación implica que el espectador reinterprete lo que no aparece. $Y$ en el proceso fotográfico se pierden datos espaciales y temporales por la selección de la cámara y por la que hace el propio operador.

De hecho, a lo largo de toda la película observamos la presencia de primerísimos planos y planos detalle, centrados en muchos casos por algún elemento del cuerpo del personaje (Ortiz Villeta, 2007:205-226). Las manos, sobre todo, son el motivo central de escenas como las del minuto 4:40, dónde podemos ver el anillo de ella cuando corre hacia el aeropuerto para recoger a su marido. $Y$ el constante roce de los dedos entre los protagonistas, como el del minuto 32. Aunque también los hay sugerentes, como aquel fotograma de un objeto tan sencillo como son unas zapatillas de casa, a modo de metáfora del punto de confianza en el que se encuentra la relación entre el Sr. Chow y la Sr. Chan -Figura 1-.

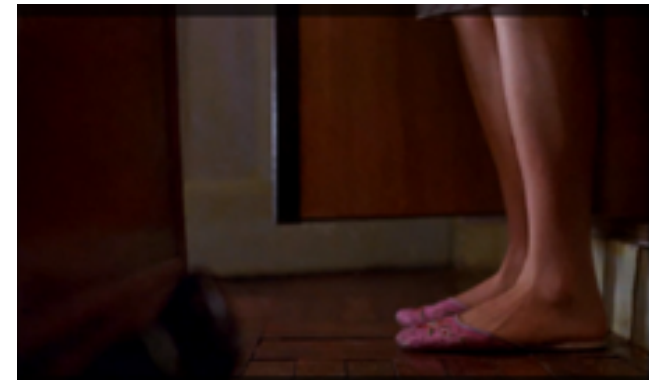

Figura 1. KAR WAI, W. Deseando Amar. Jet Tone Production, 2000.

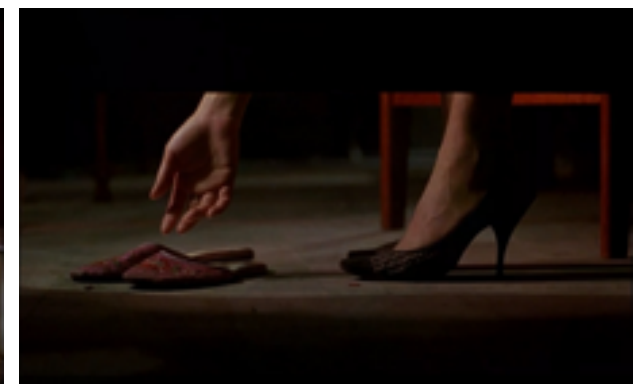

Figura 2. KAR WAI, W. Deseando Amar. Jet Tone Production, 2000.

Además, cómo explica Villafañe (2006: 186), es muy habitual también el uso de los planos vacíos que preceden a la aparición o desaparición de los personajes en la secuencia. Escenas sin movimiento con conversaciones en las que no se ven todos los implicados o que preceden a la aparición de algo -a veces acompañándolos con un travelling-. Algo que fuerza a recrearnos en una escena o a esperar que ocurra lo inesperado. De hecho, este recurso es muy habitual en el cine japonés, como es el caso de las películas de Yasuhiro Ozu y Kenji Mizoguchi (Gómez Tarín, 2013: 137).

Así, en el último tercio del filme, observamos desde un punto de vista a ras del suelo y debajo de la cama, unos pies sobre tacón de aguja, parados frente a una zapatillas de mujer -Figura 2-. Para pasar a otra en la que la mano de esa mujer aparece desde fuera de campo para tomar 
dicho calzado. Quedando claro que Wong Kar-wai desea que observemos con detenimiento. Sin pensar que algo puede entrar en el plano de manera imprevista.

Lo interesante de este filme no está en la norma, sino en su ruptura. Lo que esta fuera del campo de visión, pero que se hace presente en el interior porque los elementos que permanecen en el encuadre nos hacen pensar que están ahí, aunque no los podamos ver físicamente.

Estas subtramas en las que el espectador se imagina muchas cosas que no aparecen, pero Wong Kar-wai sugiere, son muchas veces mostradas en secuencias dónde aparecen y desaparecen los personajes.

Al comienzo del largometraje -minuto 6-, tras visualizarse un plano de las piernas del Señor y la Señora Chan, ella sale de la habitación, manteniendo la conversación con su marido. Pero en la escena, tan solo observamos un primer plano de ella mirando hacia el interior de la misma.

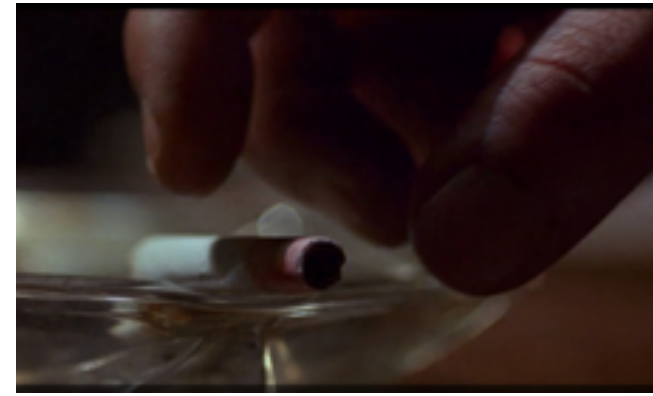

Figura 3. KAR WAI, W. Deseando Amar. Jet Tone Production, 2000

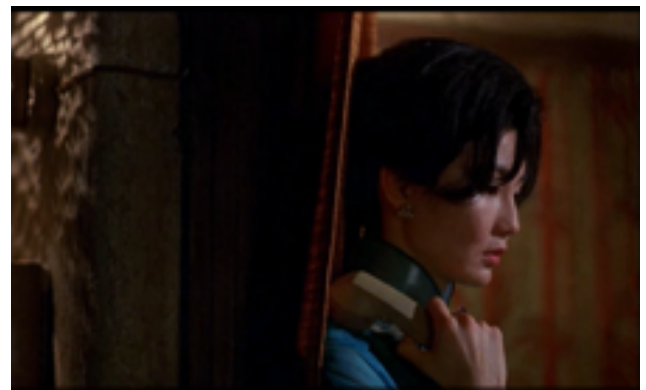

Figura 4. KAR WAI, W. Deseando Amar. Jet Tone Production, 2000.

Ni qué decir de la conversación del minuto 10:40 de la película, en la que el Sr. Chow da las gracias al Sr. Chan por haberle traído una máquina de hervir arroz para su mujer, pero a este último tan solo se le escucha en off. O el caso del Sr. Chow ya en Singapur, cuando descubre que alguien ha entrado en su habitación porque observa bajo una lámpara, una colilla manchada de carmín tirada en su cenicero -Figura 3-. Incluso la llamada que ella le hace a él, pero en la que decide tan solo escuchar sin pronunciar palabras -Figura 4-.

\subsection{Iluminación.}

Fotografiar es escribir con luz. Y la luz es la que define el volumen ocupado por el objeto en medio del espacio que le rodea, señalando su verdadera perspectiva, relieve y estructura.

Adentrándonos un poco más en el trabajo de los departamentos artístico y fotográfico, descubrimos que las escenas exteriores generalmente están grabadas con la propia luz natural. Por eso en las escenas callejeras, el ambiente nocturno posee un resultado grisáceo propio del clima tropical constantemente nublado de la ciudad oriental.

En el caso de las escenas interiores, al filmar en localizaciones reales -en su mayoría ambientes urbanos y callejeros de Hong Kong-, es el propio espacio el que le daba la luz que necesitaba, por medio de lámparas, fluorescentes, neones, o incluso la luz solar que entra por la ventana. Por lo tanto, se aprovecharon al máximo las condiciones ambientales.

En cambio, para determinadas escenas observamos luces más puntuales, con las que enfati- 
zar y dramatizar más la acción. Dirigiendo así nuestra mirada hacia un determinado personaje o sobre un fondo totalmente oscuro y apagado. De hecho, esta idea que imita el estilo tenebrista, es perfectamente entendida por el fotógrafo Eugenio Recuenco, cuando se basó en este largometraje y la popularmente concebida como su segunda parte 2046 (2003), para elaborar la campaña publicitaria para Loewe, protagonizada por la modelo Jennifer Pugh. (Recuenco, 2009)

Además, Doyle tiende a saturar determinados colores, gracias a la película y el tipo de revelado que usa ${ }^{(3)}$.

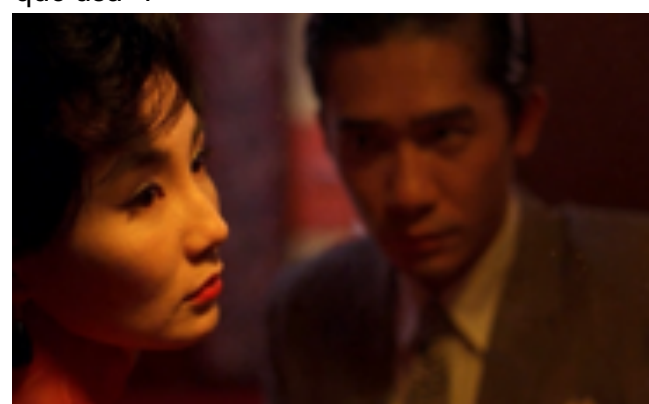

Figura 5. KAR WAI, W. Deseando Amar. Jet Tone Production, 2000.

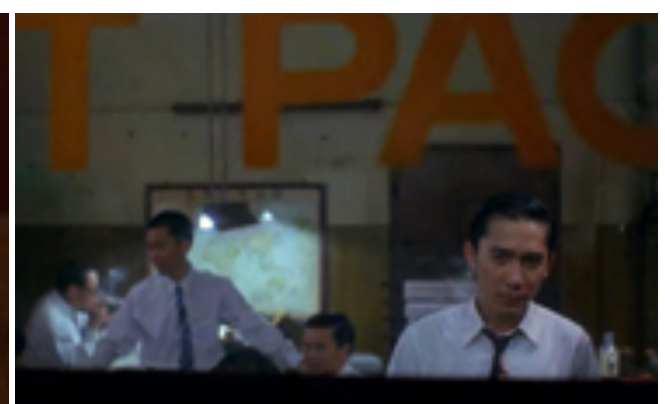

Figura 6. KAR WAI, W. Deseando Amar. Jet Tone Production, 2000.

Una película estándar está calibrada para su uso con luz de mediodía, cuya temperatura habitual es de $5500^{\circ} \mathrm{K}$, la misma que se consigue con los flashes electrónicos. Sin embargo, si la empleamos con una luz de temperatura de color inferior, se obtendrán dominantes de color que, si usamos de forma adecuada, aportarle a la fotografía un resultado que active determinadas emociones en el espectador. $Y$ dependiendo de la secuencia en la que nos situemos, podemos observar una pequeña inclinación hacía unos colores u otros.

Por ejemplo, en las secuencias de acercamiento entre los dos personajes, como en los encuentros en la habitación 2046, se aprecian colores y matices rojos -Figura 5-. Mientras que en las secuencias de soledad o tristeza podemos apreciar tonos más fríos y azulados, como es el caso de las escenas en oficina, con una temperatura de color de una dominante fría azul verdoso -Figura 6 -.

Dado que la luz se propaga en línea recta, los objetos iluminados dibujan sombras nítidas detrás de ellos y proyectan sus contornos, de mayor o menos tamaño, en función de la cercanía del objeto respecto a la luz. Por eso cualquier fotógrafo experimentado sabe que, para entender el comportamiento de la luz, hay que observar a su sombra.

Concretamente, las sombras que aparecen en el largometraje, como si se tratara de una casualidad que acabó convenciendo al director, podemos comenzar a apreciarlas como evidentemente protagonistas de los espacios encuadrados, ya en el minuto 31, cuando los personajes principales pasean lentamente por la calle.

Pero no es la única escena en la que lo comprobamos. En una de esas caminatas con los amantes, observamos cómo las sombras proyectas de unos barrotes, no solo se usan como recurso estético o puramente compositivos, como es el caso de proyección de la sombra de 
una persiana o las sombras simétricas de una lámpara de pared. Sino que aquí además aportan cierta sensación de aprisionamiento de los sentimientos de los personajes.

\subsection{Punto de vista, ángulo de visión y óptica.}

La lente fotográfica tiene una visión pura de lo que ve -sin prejuicios del operario- y cámara registra sobre el material sensible -sensor o negativo- la decisión tomada por el ojo. Pero somos nosotros -los operarios- los que seleccionamos cuándo filmar. Por tanto, es necesaria la unión de un ojo adiestrado y una mente con imaginación. Lo que implica que dicha búsqueda debe acabar en una adecuada selección con la que estar convencidos.

La óptica juega un papel importante al invitar a jugar con la perspectiva, a variar la distancia de la cámara a la escena, e incluso al permitir visionar las cosas situadas a una distancia inferior a la del enfoque mínimo del ojo humano.

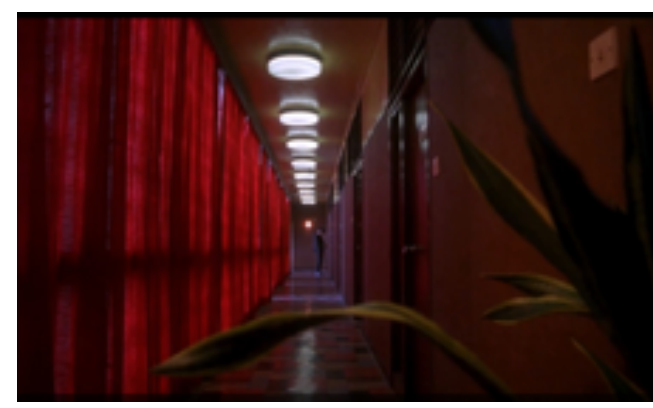

Figura 7. KAR WAI, W. Deseando Amar. Jet Tone Production, 2000.

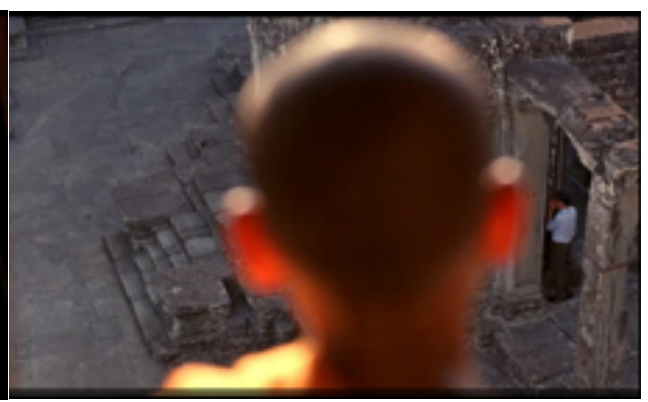

Figura 8. KAR WAI, W. Deseando Amar. Jet Tone Production, 2000.

Al caso, Deseando Amar (2000) posee muchas escenas en las que las perspectivas se marcan linealmente y con un punto de fuga que nos dirige la mirada de un modo intencionado. Es lo que ocurre cuando se muestran los pasillos del hotel donde se acaban escondiendo los amantes. Una perspectiva lineal, en la que Doyle se recrea, sin más pretensión que enseñar la belleza del lugar -Figura 7-.

Sin embargo, lo realmente interesante no solo es el uso que hace de los grandes angulares, para destacar el primer plano de ciertos gestos u objetos, o el de los puntos de vista contrapicados y picados. Sino también el de los enfoques selectivos y de las escenas completamente fuera de foco.

Así, en un primer plano, totalmente centrado, observamos la nuca desenfocada del muchacho budista del último bloque de la película en Camboya -Figura 8-. Pero en el fondo, a la derecha, el Sr. Chow queda enfocado, mientras cuenta su secreto al agujero de la pared. Entre medias, apreciamos una secuencia de vistas en la que nos muestran primeros planos y planos generales, desde distintos puntos de vista.

Un alarde de dominio técnico en el que se mezclan escenas tratadas con total definición -como si quisiera demostrar un conocimiento de la fotografía arquitectónica, en la que se hace imprescindible un resultado con máxima profundidad de campo-, con otras en las que reina el desenfoque, como recurso estético vinculado a la fotografía. 
Y es que resulta curioso como Wong Kar-wai apuesta por el uso de un resultado en el que la estética ha superado a la técnica, para obligar al espectador a observar con más detenimiento la escena. Por eso, al final del filme, nos enseña durante unos segundos algo que no quiere se nos quede claro en la retina. A la Sr. Chan, en una habitación que parece ser la misma del comienzo de esta historia, recogiendo a un niño pequeño -todo apunta que suyo-, con la compañía de una sirvienta que igualmente nos recuerda a Amah -Figura 9-. Por lo tanto, estamos ante un claro ejemplo del uso de la técnica fotográfica para potenciar la elipsis en esta película.

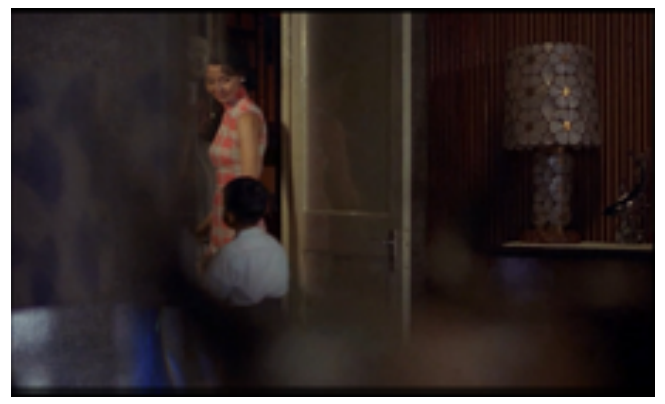

Figura 9. KAR WAI, W. Deseando Amar. Jet Tone Production, 2000.

\subsection{Simetría.}

Es la correspondencia exacta en forma, tamaño y posición de las partes de un todo, respecto a un mismo eje central, a modo de espejo y reflejo ${ }^{(4)}$.

Este sistema perceptivo podemos encontrarlo de un modo muy curioso. $Y$ es que existen secuencias en las que, desde la vista de una escena a la siguiente, encontramos un juego simétrico, tan solo perceptible al situarlas uno al lado de la otra, como si fueran dípticos.



Figura 10. KAR WAI, W. Deseando Amar. Jet Tone Production, 2000.

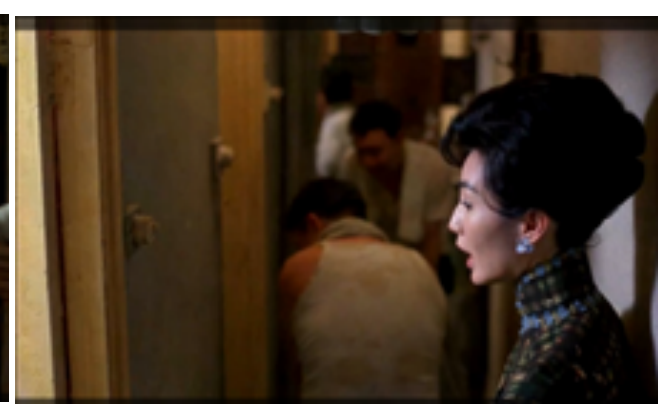

Figura 11. KAR WAI, W. Deseando Amar. Jet Tone Production, 2000

Al inicio de la película, existe un momento en el que se observa cómo las mudanzas de ambos personajes principales coinciden en el mismo tiempo. Pero no solo eso, sino que además la puesta en escena que se produce cuando dan indicaciones desde el pasillo hacia el interior de las habitaciones, dónde los transportistas colocan sus cajas y objetos, es totalmente simétrica. De hecho, eso potencia la propia historia en la que se expone que existe una confusión entre las propiedades de ambos futuros vecinos -Figuras 10 y 11 -

Del mismo modo, el Sr. Chow y la Sra. Chan toman té uno frente al otro, en la misma mesa del 
restaurante donde se confiesan que saben lo que está ocurriendo entre sus respectivos cónyuges -Figuras 12 y 13-. El plano medio desde la nariz hasta el pecho, muestra la importancia que Wong Kar-wai le da a las manos. Con una luz cálida muy impropia de este tipo de lugares, la sensación de cercanía entre ambos, se mezcla con el sentido hiriente de las palabras. Y como si desfragmentaran los detalles en los que desea que nos centremos, sus rostros demuestran la perplejidad con la que admiten la verdad.

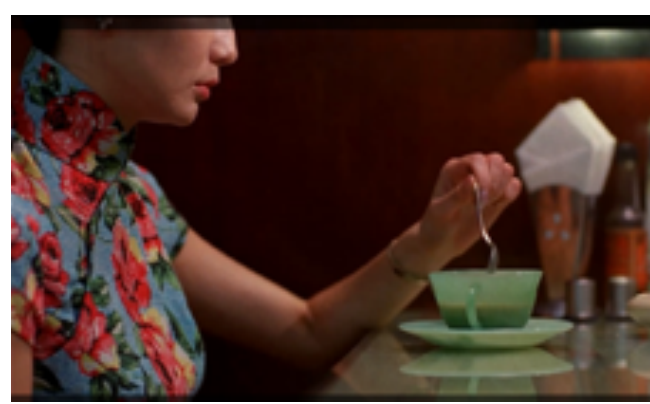

Figura 12. KAR WAI, W. Deseando Amar. Jet Tone Production, 2000.



Figura 13. KAR WAI, W. Deseando Amar. Jet Tone Production, 2000.

Pero, a la que vez que equilibrada, la composición simétrica corre el riesgo de ser monótona. Por eso Wong Kar-wai juega con la llamada asimetría. El mejor ejemplo lo encontramos en aquella escena donde los amantes quedan atrapados en su habitación y en la que los espejos juegan un papel de amplitud inesperado. Recurso que se repite ya en la habitación 2046, en la que los amantes van tomando confianza, sin reprimir sus sentimientos. De hecho, se trata de una secuencia en la que los protagonistas interactúan dentro de una habitación con dos espejos en los extremos y una mesa central. Gracias a ello observamos las continuas miradas que se regalan -Figuras 14 y 15 -.

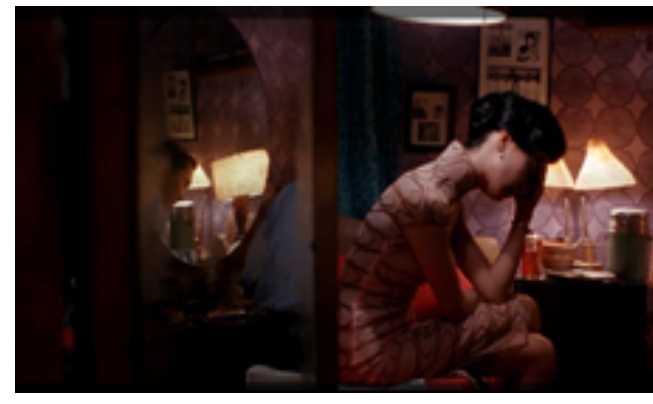

Figura 14. KAR WAI, W. Deseando Amar. Jet Tone Production, 2000.

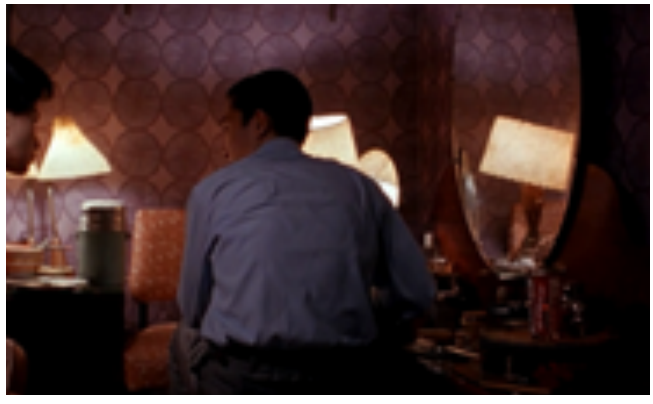

Figura 15. KAR WAI, W. Deseando Amar. Jet Tone Production, 2000.

\subsection{Reflejos.}

Wong Kar-wai, en su búsqueda por dejar que sea el espectador quién imagine, más que mostrarle todo hecho, decide hacer también uso reiterado de los reflejos. Pero no solo en los espejos, sino en cualquier superficie especular. 
Hay varios casos que llaman la atención por su finalidad estética. En el primero podemos ver como el Sr. Chow se asoma al pasillo, reflejado por un espejo, para comprobar que no van a poder salir de la habitación durante un largo periodo de tiempo -Figura 16-. En el segundo, Ping acaba de preguntarle a su compañero sobre sus secretos, recibiendo como respuesta una evasiva. Finalizando la escena con ese reflejo de Ping fumando, en el que vemos su expresión disconforme -Figura 17-. Y la tercera, es el momento en el que nuestro protagonista acude al hotel donde trabaja su esposa, para darle una sorpresa. Descubriendo finalmente que ésta le ha engañado. En la escena, el sr. Chow se apoya en la recepción, mientras su hombro se refleja sobre un espejo en primer plano que interpretamos, completa la figura de ese personaje que no se ve tras la pared -Figura 18-.

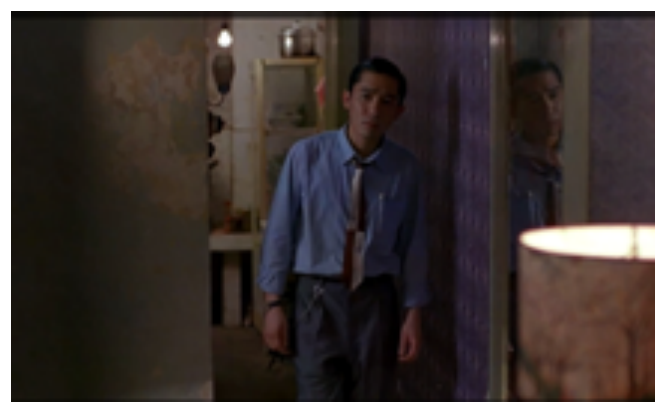

Figura 16. KAR WAI, W. Deseando Amar. Jet Tone Production, 2000.



Figura 17. KAR WAI, W. Deseando Amar. Jet Tone Production, 2000.

\subsection{Tiempo.}

Se refiere a la "magnitud física que permite ordenar la secuencia de los sucesos, estableciendo un pasado, un presente y un futuro, y cuya unidad en el sistema internacional es el segundo"(5). Aunque existen muchos autores que han intentado concretar su sentido.

En la fotografía fija, dicho tiempo lo controlamos con la velocidad de obturación. Pero en la imagen cinematográfica, cuando hablamos del paso del tiempo, nos referimos a la idea del tiempo como duración y, por tanto, debemos hablar también del movimiento.

Concretamente, el tiempo también es la parte de una secuencia y se puede definir como la unidad de división de un relato visual, formando parte de una sucesión ordenada de planos o escenas que guardan relación entre sí. Por lo tanto, una secuencia reproduce un esquema temporal de la realidad dotado de significación, en el que espacio y tiempo tienen la misma importancia. Podemos decir que su forma de representación es narrativa y puede ser representada en distintos tiempos y espacios.

Al caso, el largometraje Deseando Amar nos enseña su particular vivencia del tiempo mediante un baile de cuerpos que se comunican a cámara lenta en un espacio atemporal e indefinido, cuando las imágenes ralentizadas se supeditan al compás de la música. Mientras, nosotros intentamos descubrir si lo que ocurre es anterior o posterior al momento que estamos visualizando.

Además, nos reta continuamente situando relojes ${ }^{(6)}$ en una escena y en la siguiente, sin importarle el "racord". Pero el espectador sí lo sabe porque los personajes nos ubican en el espacio 
geográfico y temporal. Son ellos quienes nos cuentan la evolución de su amor, a base de pistas que nada tienen que ver con el tiempo, tal y como se representa en el largometraje. Pero no solo eso, sino que existen secuencias, como es el caso del bloque 'Simulación' (Gómez Tarín, 2013: 71), en las que aparentemente hay una sucesión de hechos que ocurren en el mismo tiempo y lugar. Sin embargo, se puede comprobar cómo Wong Kar-wai vuelve a crear confusión, cambiando de traje a la Sr. Chan de una escena a otra. Por lo tanto, estamos ante un flashback o un flashforward -según se mire- gracias al montaje.

Ortega y Gasset (2009) empleó el término 'ucronía' para referirse a algo que sucede en cualquier tiempo, fuera del propio tiempo, porque no importa cuándo ha tenido lugar el hecho, sino que haya sucedido. Se trata de subrayar el hecho en sí como elemento perturbador y desencadenante de consecuencias. De este modo, al difuminar anclajes y referencias espacio-temporales, Wong Kar-wai consigue que la vivencia privada entre dos sujetos se convierta en la experiencia universal de deseando amar.

En definitiva, está claro que la finalidad de este largometraje no es otra que tratar al espectador de manera inteligente, dejando que construya la historia sin ser complaciente. Para ello, no solo hace uso de los silencios dónde debe haber ruido, los vacíos sonoros y visuales, las miradas hacia algún lugar fuera de campo, los subtextos y las conversaciones incompletas o que simplemente no se tienen.

De hecho, la trama evoluciona de una manera sutil por medio de fotogramas en los que se cuenta como se está evolucionando una historia de amor frugal, fuera de campo y en la que la verdad posee distintas caras. Por eso no muestra todo de golpe -ni ubicaciones, ni tiempos concretos-, sino que lo hace con cuentagotas.

Al respecto, podemos afirmar que el apoyo que se hace en los fuera de campo, incluso los desenfoques o las distorsiones, a pesar de oponerse al acabado perfeccionista que resalta en toda la película, han servido para potenciar la presencia de múltiples elipsis a lo largo de todo el largometraje. Como es el caso de las distorsiones ópticas provocadas conscientemente, aun sabiendo que Doyle cuenta con el suficiente control sobre la cámara como para no dejar que este tipo de fallos aparezcan en el largometraje. Además del insistente uso de los desenfoques para que no se entre en la intimidad de los protagonistas desde el principio. Sino que poco a poco, descubramos sus espacios personales, sin darnos cuenta de que lo estamos haciendo. Los continuos fuera de campo, para sugerir en vez de mostrar. Los enfoques selectivos y los puntos de vista extremos. O los reencuadres en el encuadre, para redirigir la mirada del espectador. $Y$ el uso del fuera de tiempo, sin importarle el racord y creando continuamente confusión, cambiando de traje a la Sr. Chan de una escena a otra en la que parece que han pasado apenas unos minutos.

Queda claro con todo lo expuesto que se cumplen los objetivos reseñados. Precisamente el uso de la mecánica fotográfica aporta resultados que tan solo ofrece dicho medio: enfoque o desenfoque a través de la óptica de los objetivos, el espacio de nitidez y profundidad de campo gracias a la apertura del diafragma o los distintos acabados en función del tipo de soporte que usemos. Pero además, el conocimiento de la idónea organización de los elementos en el encuadre, nos permite hablar de tipos de composición, puntos 
de vista, usos de distintos planos y sus efectos en el espectador. Se corrobora por tanto también la hipótesis planteada y en ello, Doyle, el director de fotografía, tiene mucho que ver. Puesto que, no solo posee un profundo conocimiento de los procesos de trabajo fotográficos, sino que también está formado en conceptos, en ideas y, sobre todo, tiene el deseo de contar. Esto es debido a que el conocimiento técnico se ha puesto al servicio de la narración para conseguir una limpieza visual, casi publicitaria, en la que se ha eliminado lo superfluo, quedándose exclusivamente con lo necesario para la narración. De esta manera, el espectador tan solo se centra en la disfrutar de las imágenes realizadas para esta historia. Además, Wong Kar-wai rueda las escenas siguiendo con rigidez la cronología de la historia. Lo que supone un coste adicional en cuanto al tiempo y recursos. Sin embargo, eso permite a los actores y al propio equipo de la película adentrarse en la historia según la propia evolución del rodaje.

Esa manera de trabajar permite a Doyle observar in situ, no solo cómo actúan las luces de cada escenario o las sombras que se proyectan sobre las distintas superficies de los espacios rodados, sino también probar con las diferentes emociones que se pueden llegar a transmitir en el espectador, en función del punto de vista desde dónde se sitúa la cámara: si más cercana o alejada de los actores, a través de ventanas o entre los objetos aparentemente molestos. $\mathrm{O}$ incluso grabando una misma secuencia, desde distintos planos -centrándose en las manos, de cuello hasta cintura, solo del rostro, de cuerpo entero o generales-, para después decidir intercalar unas secuencias con otras o simplemente, eliminarlas. Con lo cual, esta manera de hacer cine permite definir muy bien el tipo de imagen que se quiere finalmente mostrar al espectador, para así poder transmitir emociones y sentimientos por medio de fotogramas que visualmente acompañen a las historias contadas.

En definitiva, todo esto hace que podamos afirmar que se trata de un largometraje en el que la maestría fotográfica de Christopher Doyle tan solo es comparable con la exhaustividad de Wong Kar-wai para seleccionar las tomas que más se adentran en las emociones y los sentimientos. Una película que supuso la ruptura con el cine tradicional chino, hasta el momento encorsetado, gracias a un cuidado inusual de las imágenes.

\section{REFERENCIAS BIBLIOGRÁFICAS}

BARTHES, R. (2009): La cámara lúcida. Barcelona, Paidós.

BRUNETTE, P. (2005): Wong Kar Wai. Contemporary Film Directors. Illinois. University of Illinois Press.

CASTELO, L. (2006): Del arte al ruido. Una interpretación de los usos no normativos del lenguaje fotográfico. Colección Imagen, Arte y Color. Número 5. Madrid, H. Blume.

CODÓ MARTÍNEZ, J. (2009): "La llegada y consumo de cines asiáticos en Occidente", en Inter Ásia Papers. № 10. Barcelona, Instituto de Estudios Internacionales e Interculturales, Universidad Autónoma de Barcelona, 2009. Disponible en Internet (10.03.2019): < $\underline{\text { https://www.raco. }}$ cat/index.php/interasiapapers/article/view/167304/219562 > 
DISSANAYAKE, W. (2003): Wong Kar Wai's Ashes of Time. The New Hong Kong Cinema. Hong Kong, Hong Kong University Press.

FONTCUBERTA, J. (coord.) (2003): Estética Fotográfica. Barcelona, Editorial Gustavo Gili.

GÓMEZ ALONSO, R. (2005): "Retórica fotográfica. Ingenio y provocación", en Icono 14, Revista de Comunicación y nuevas tecnologías, n 1, 2005. Disponible en Internet (20.06.2019) < file:///Users/diegomartin/Downloads/Dialnet-RetoricaFotograficalngenioYProvocaci on-5298455\%20(1).pdf>

GOMEZ TARÍN, F.J. (2003): "Lo ausente como discurso: elipsis y fuera de campo en el texto cinematográfico". Tesis doctoral, Universidad de Valencia. Disponible en Internet (20.06.2019) <https://www.tdx.cat/handle/10803/10309>

GOMEZ TARÍN, F.J. (2013): Deseando Amar. Colección Guías para ver y analizar. № 52, Valencia, Nau Llibres.

GÓMEZ TARIN, J. (2008): Wong Kar-Wai: Grietas en el espacio tiempo. Madrid, Akal.

GONZALEZ REQUENA, J. (1992): "Clásico, manierista y postclásico", en Área 5. Revista de Comunicación Audiovisual y Publicitaria, № 5. Madrid, pp. 15-22, 1992. Disponible en Internet (20.01.2019) <http://www.gonzalezrequena.com/resources/1996\%20Clásico,\%20 Manierista,\%20Postclásico.pdf>

GOODRIDGE, M. ; GRIERSON, T. (2012): Dirección de fotografía cinematográfica. El arte del cine. Barcelona, Blume.

KAR WAI, W. (2004): 2046. Jet Tone Production.

KAR WAI, W. (2000): A note on the making of in the Mood for Love. [Documental].

Parte 1. Disponible en Internet $(20.06 .2019)<$ https://www.youtube.com/

watch?v=VaixZLzYAKI >

Parte 2. Disponible en Internet $(20.06 .2019)<\underline{\text { https://www.youtube.com/ }}$ watch? $v=$ XsbWOL6H-uE >

KAR WAI, W. (2000): Deseando Amar -In the Mood for Love. Jet Tone Production. Disponible en Internet (04.04.2019) < https://mega.nz/\#!W2p0mAqD!QAjraQSHK6AlfF4b9dmScARilydWkZ-cb3DgM-T5Ro>

KRACAUER, S. (2001): Teoría del cine. La redención de la realidad física. Barcelona, Paidós Comunicación Cine.

LAGUILLO, M. (1995): ¿Por qué fotografiar? Escritos de circunstancias 1982- 1994. Colección Palabras de arte. Número 1. Murcia, Mestizo.

MARTÍNEZ ABADÍA, J.; FERNÁNDEZ DÍEZ, F. (2010): Manual del productor audiovisual. 
Barcelona, Editorial UOC. Disponible en Internet $(08.04 .2019)<\underline{\text { http://docplayer. }}$ es/64404255-Manual-del-productor-audiovisual.html>

MARTIN FERNANDEZ, D. (2018): “Observar, decidir y disparar la cámara fotográfica. Un análisis de las preferencias de los usuarios", en Revista ArtyHum. Revista Digital de Arte y Humanidades. № 53, p. 128. Disponible en Internet (03.07.2019) < https://www.artyhum.com/ revista/53/mobile/index.html\#p=110>

ORTEGA Y GASSET, J. (2009): La deshumanización del arte. Madrid, Alianza Editorial.

ORTIZ VILLETA, A. (2007): "Paisaje con figuras. El espacio habitado del cine", en Revista Saitabi, No. 57, Pp. 205-226, 2007. Disponible en Internet (25.02.2019) < https://dialnet.unirioja. $\underline{\text { es/servlet/articulo?codigo }=2925785>}$

PROTSENKO, V. (2018): "Más allá de la nostalgia poscolonial: los melodramas Deseando Amar y 2046 de Wong Kar-wai", en L'atalante. Revista estudios cinematográficos. La pervivencia de la nostalgia. № 25. Valencia, Enero, Junio 2018. Disponible en Internet (25.06.2019) < http://www.revistaatalante.com/index. http://www.revistaatalante.com/index. php?journal=atalante \&page =article \&op=view \&path $\% 5 B \% 5 D=532 \&$ path $\% 5 B \% 5 D=472>$

RECUENCO, E. (2009): Quizás, quizás, quizás. [Campaña publicitaria]. Loewe. Disponible en Internet $(01.04 .2019)$ < https://www.youtube.com/watch?v=OboMeadC GM >

SONTAG, S. (2006): Sobre la fotografía. Madrid, Editorial Alfaguara.

VILLAFAÑE, J.; MINGUEZ, N. (2006): Principios de Teoría General de la Imagen. Madrid, Ediciones Pirámide.

WEB PROPUESTA DE MODELO DE ANÁLISIS DE IMAGEN. Disponible en Internet

\section{NOTAS:}

(1) Se refiere a aquella actividad relacionada con un oficio que implica tener un conocimiento profundo, estar instruido, ser hábil o diestro en la producción visual. (Martín Fernández, 2018: 129-131)

(2)Luis Castelo (2006), citando a Jacques Aumont, lo define "aumont" (martyco o límite de la imagen).

(3) Kodak Visión 500T 5279 y Kodak Visión 800T 5289/7289. Estas películas ofrecen un grano muy fino y una mayor nitidez, además de colores vivos y una amplia gama de exposición con sombras y luces.

(4) Según la Real Academia de la Lengua Española, en su primera acepción.

(5) Según la Real Academia de la Lengua Española, en su segunda acepción.

(6) Se podría considerar un estilema por ser una repetición propia del estilo de un autor. 
CURRICULUM VITAE: Diego Martín Fernández (Málaga, 1982)

Doctor en Bellas Artes por la Universidad de Barcelona. Posee el Máster de Cinematografía de la Universidad de Córdoba. Comenzó siendo fotógrafo del Diario Ideal de Granada. En 2011 obtuvo la plaza del Profesor Titular de Fotografía del Cuerpo de Profesores de Artes Plásticas y Diseño. Y desde 2015 a 2019, fue Director de la Escuela de Arte Algeciras. Ha realizado comunicados para congresos sobre fotografía e investigación en artes visuales. $Y$ sus imágenes han ilustrado libros y carteles para congresos sobre salud pública, criminología, el medio ambiente y las migraciones sociales. Cuenta con distintos premios internacionales y su obra forma parte de varias colecciones de arte. 